\title{
Missense mutation in SLIT2 associated with congenital myopia, anisometropia, connective tissue abnormalities, and obesity
}

Katherine Y. Liu', Jesse D. Sengillo ${ }^{3,4}$, Gabriel Velez ${ }^{5,6,7}$, Ruben Jauregui ${ }^{3,8}$, Lynn Y. Sakai ${ }^{9}$, Irene H. Maumenee ${ }^{3}$, Alexander G. Bassuk ${ }^{10}$, Vinit B. Mahajan ${ }^{5,6,11}$ and Stephen H. Tsang $2,3,12,13^{*}$

\begin{abstract}
Background: SLIT2 is a protein ligand for the Roundabout (ROBO) receptor and was found to play a major role in repulsive midline axon guidance in central nervous system development. Based on studies utilizing knockout models, it has been postulated that SLIT2 is important for preventing inappropriate axonal routing during mammalian optic chiasm development.

Methods: Case report.

Results: Here, we report a case of congenital myopia, anisometropia, and obesity in a patient with a SLIT2 point mutation. Examination of the patient's skin biopsy revealed abnormalities in elastin and collagen fibrils that suggest an underlying connective tissue disorder. Structural modeling placed the novel mutation (p.D1407G) in the EGF-like domain 8 and was predicted to affect interactions with SLIT2 binding partners.
\end{abstract}

Conclusions: To the authors' knowledge, this is the first report of a SLIT2 variant in the context of these ocular findings.

Keywords: SLIT2, Myopia, Anisometropia, Structural modeling, Precision medicine, Obesity

\section{Background}

Myopia is the most common ocular disorder. High-grade myopia is a leading cause of visual impairment and blindness worldwide, particularly due to associated comorbidities that include retinal detachment, localized retinal degeneration, premature cataract and glaucoma. Multiple genetic syndromes with extraocular findings manifest with myopia as a clinical feature, including the autosomal dominant connective tissue disorders Marfan syndrome and Stickler syndromes type 1 and 2, all of which can be traced back to defects in fibrillin, COL2A1, and COL11A1 genes, respectively [1]. Non-syndromic high-grade myopia is frequently early

\footnotetext{
* Correspondence: gene.editing@gmail.com

2Jonas Children's Vision Care, and Bernard and Shirlee Brown Glaucoma Laboratory, New York, USA

${ }^{3}$ Department of Ophthalmology, Columbia University, New York, NY, USA Full list of author information is available at the end of the article
}

onset and congenital. Congenital myopia is generally regarded as a multi-factorial polygenic disorder. The role of genetic factors in the development of non-syndromic congenital myopia is not clearly understood due to the wide clinical spectrum and genetic heterogeneity of this condition. Multiple twin studies demonstrated evidence of the heritability of myopia, including increased concordance of refractive error and refractive components (axial eye length, corneal curvature, lens power, anterior chamber depth) in monozygotic twins compared with dizygotic twins [2]. The estimated heritability estimates from twin studies range from 0.5 to 0.96 . The chance of an individual having myopia if their sibling is affected, expressed as a ratio to the general population, is approximately 4.9 to 19.8 for siblings for high-grade myopia (-6.00 spherical D or greater), and approximately 1.5 to 3 for low-grade or common myopia (approximately -1.00 to -3.00 spherical $D$ ), suggesting the presence of genetic 
risk factors for both high-grade myopia and low-grade myopia [3].

Additionally, multiple genetic loci associated with myopia are identified. The largest linkage scan to date for familial high-grade myopia utilized whole exome sequencing data from 254 families from five independent sites, demonstrating linkage replication of the high myopia loci MYP1, MYP3, MYP6, MYP11, MYP12, and $M Y P 14$, and identifying a novel locus at chromosome 9q34.11 [3, 4]. Other studies have identified implicated genes. For example, autosomal-recessive high-grade myopia was reported in a large consanguineous Israeli Bedouin kindred. Genetic analysis and sequencing of the exons of six genes identified a point mutation c.1523G > $\mathrm{T}$ in the exon 10 of the LEPREL1 gene [5]. The uromodulin-like 1 (UMODL1) gene, which was previously prioritized during a whole-genome case-control association analysis in high-myopia Japanese patients, has been found to have one significant SNP within its frequent recombinant region, supporting the gene's potential role as a disease susceptibility gene. A case control study of mixed ethnicities showed an association between myopia and 2 SNPs in the collagen 2 alpha 1 gene (COL2A1), which maps to chromosome 12q13.11 and has been associated with familial Stickler syndrome type 1. A retrospective analysis of patients with type II collagenopathy chondrodysplasia further revealed that over $85 \%$ are myopic, suggesting that myopia may result from defects in type II collagen in these cases [4]. These studies underscore the inherent complexity of myopia and the potential genetic factors contributing to refractive error.

The SLIT2 protein is a major ligand for the Roundabout (ROBO) receptor and was initially found to play a major role in repulsive midline axon guidance in $\mathrm{CNS}$ development [6-10]. In humans, SLIT Homolog 2 (SLIT2), was mapped to chromosome 4p15.2 [6, 7]. In healthy individuals, SLIT2 is expressed in a wide variety of tissues, such as connective and adipose tissue, heart, brain, eye, vasculature, and kidney. SLIT/ROBO paired signaling is now known to be critical for a wide variety of morphogenetic processes, such as chemotaxis, angiogenesis, kidney and cardiac development. It has also been shown to impede the pathologic formation of blood vessels [11-15]. SLIT2 is also now known to be important for the establishment of the polarity of newly differentiated retinal ganglion cells (RGC) along the optic pathway [16]. Further, the full-length SLIT2 protein $(180 \mathrm{kDa})$ is cleaved into a $130 \mathrm{kDa} \mathrm{N}$-terminal fragment (termed SLIT2-N) and a $50 \mathrm{kDa}$ C-terminal fragment (SLIT2-C). The SLIT2-C fragment has been found to play a key role in regulating glucose homeostasis and energy expenditure in adipocytes by activating PKA-dependent signaling pathways [17]. Human mutations in SLIT2 have been previously-identified in patients with congenital abnormalities of the kidney and urinary tract (CAKUT) and recurrent mutations have been detected in patients with small-cell lung cancer $[18,19]$. In this case study, we report a novel tetrad of congenital myopia, anisometropia, obesity, and connective tissue abnormalities in a patient with a variant in SLIT2, c.4220A > G (p.D1407G).

\section{Methods}

\section{Phenotypic ascertainment}

The patient underwent an ophthalmic examination which included spectral domain-optical coherence tomography (SD-OCT) images and fundus autofluorescence (AF) images, which were acquired using a Spectralis HRA + OCT (Heidelberg Engineering, Heidelberg, Germany). Full field electroretinograms (ffERG) were obtained using the Diagnosys Espion Electrophysiology System (Diagnosys LLC, Littleton, MA, USA) and Ganzfield stimulation per international standards. The pupils were maximally dilated before full-field ERG testing using guttate tropicamide (1\%) and phenylephrine hydrochloride (2.5\%). Additionally, the corneas were anesthetized with guttate proparacaine $0.5 \%$.

\section{Genetic testing}

Whole exome sequencing, bioinformatics analysis, and filtering based on autosomal and X-linked dominant and recessive and Y-linked inheritance models of the proband, mother, father and maternal aunt were conducted at Ambry Genetics Laboratory. Manual review to rule out sequencing artifacts and polymorphisms along with medical interpretation to rule out genes lacking clinical overlap with the patient's evaluated phenotype resulted in one candidate gene with likely clinical relevance that was selected for further investigation via co-segregation analysis.

\section{Structural modeling of human SLIT2}

The leucine-rich repeat domains (LRR1-4; residues 30909) were modelled off the mouse Toll-like receptor-9 structure (PDB: 3WPF; 24\% sequence identity) [20]. and the human SLIT2 dimerization domain D4 (PDB: 2WFH; $100 \%$ sequence identity) using MODELLER 9.14 [21, 22]. The structure of the EGF-like repeats 1-6 (residues 9181157) were modelled off the Notch1 crystal structure (PDB: 5UK5; 39\% sequence identity) [23]. The structure of the laminin $C$ domain was modeled off the laminin alpha structure (PDB: 1OKQ; 31\% sequence identity) [24]. The structure of EGF-like repeats 7-9 were modelled off the Notch1 ligand Delta-like 1 structure (PDB: 4XBM; 98\% sequence identity) [25]. There were no homologous structures in the Protein Data Bank for the C-terminal cysteine knot (CTCK) domain. We therefore modeled this domain using an ab initio approach in Phyre2 [26]. The individual 
domain models were then assembled through ab initio domain assembly using the AIDA program [27]. In silico mutagenesis was performed using FoldX [28]. Electrostatic potentials were calculated using APBS [29]. Protein and solvent dielectric constants were set to 2.0 and 78.0, respectively. PyMOL generated all structural figures [30].

\section{Results}

A 15-year-old boy presented to the Harkness Eye Institute electroretinography clinic. Initially, best-corrected visual acuity was 20/50 in the right eye and 20/40 in the left eye. His past medical history was significant for obesity and conception through IVF (Additional file 1: Table S1) [31]. Family history was unremarkable. His older brother was unaffected and had no visual complaints (Fig. 1a). Systemic evaluation showed mild joint laxity bilaterally in the upper and lower extremities and mildly doughy skin particularly in the ears. There were no known congenital kidney anomalies reported by history. The proband never achieved 20/20 vision as per history. The proband's vision was 20/50 in the right eye and 20/40 in the left eye since 18-months-of-age. His mother has been patching the left eye since 18-months-of-age. Yearly follow-up examinations showed no signs of either strabismus or nystagmus. The anterior segment examination appeared to be quiet and without cataracts. The corneas were clear and extraocular eye movements were symmetric and full. On dilated

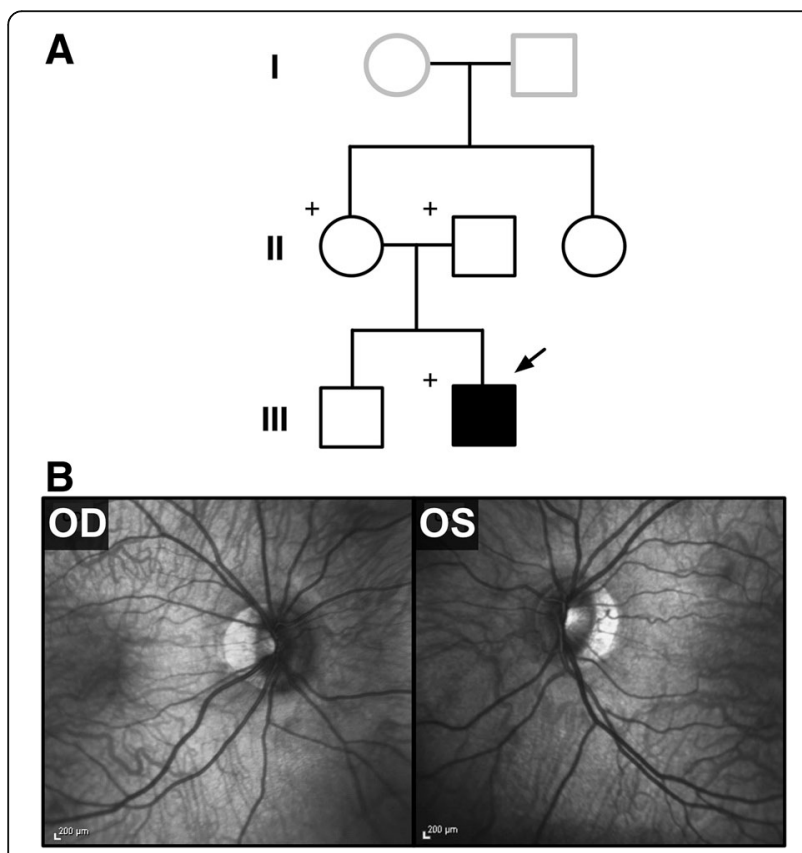

Fig. 1 Clinical examination of a patient with myopia, anisometropia, obesity, and connective tissue abnormalities: a Pedigree of the proband family. The patient in this family is the only one presenting with ocular disease. The $(+)$ denotes family members who underwent whole exome sequencing. b Dilated fundus examination reveals peri-papillary atrophy of the optic nerve, seen also in SD-OCT fundus examination, the patient's optic nerve presented with a good rim and peripapillary atrophy, a common finding in the general population, and is shown on spectral domain optical coherence tomography (SD-OCT) (Fig. 1b). Multifocal electroretinogram testing was performed per ISCEV standards with 61 hexagons. The waveforms were mildly reduced compared to normal and were consistent with macular dysfunction. The axial length of patient's right eye increased from $26.94 \mathrm{~mm}$ in January 2010 to $27.75 \mathrm{~mm} 3$ years later, further increasing to $28.55 \mathrm{~mm}$ as measured in his latest clinic visit on January 2017. The axial length of patient's left eye has increased from $25.67 \mathrm{~mm}$ in January 2010 to $26.75 \mathrm{~mm} 3$ years later, further increasing to $27.73 \mathrm{~mm}$ on January 2017. Refraction was -7 sphere with -4 cylinder at 22 degrees and 4.25 sphere with -2.25 cylinder at 142 degrees for the right and left eye, respectively. On examination in January 2017 , refraction progressed to -9 sphere with $-4.75 \mathrm{cy}$ linder at 25 degrees and -7 sphere with -3.5 cylinder at 152 degrees for the right and left eye, respectively.

Full field electroretinogram (ffERG) testing showed scotopic rod specific ERG b-wave amplitudes were 159 microvolts in the right eye and 156 microvolts in the left eye. Photopic $30 \mathrm{~Hz}$ flicker ERG had amplitudes were 25 microvolts in the right eye and 29 microvolts in the left eye. Scotopic and photopic responses exhibited no implicit time delays (Fig. 2). After three-years, the patient's visual acuity was found to be best corrected to $20 / 40$ in the right eye and $20 / 30$ in the left eye, remaining relatively stable over follow-up.

A skin biopsy was performed and examined by light microscopy. Examination by light microscopy revealed multiple abnormalities. A considerably thickened epithelium was present, particularly near the hair follicles (Fig. 3a), along with a high density of collagen in the papillary dermis (Fig. 3b). Furthermore, there are large deposits of microfibrils adjacent to the basement membrane, which is often seen in tissue that is repeatedly injured. The elastin in the shallow and deep papillary dermis is moth-eaten and lacks associated microfibrils, which would not be expected in a child (Fig. 3c). The biopsy also showed macrophages adjacent to the capillaries (Fig. 3d) and dimples at the cores of the elastin fibrils that indicated a higher than normal density of elastin fibrils in the reticular dermis (Fig. 3e). The collagen fibrils in the reticular dermis were also abnormally small and uniform in diameter (Fig. 3f).

Whole exome sequencing was performed on the peripheral blood of the proband and his family members, including parents, brother and maternal aunt. No coding variants were identified in known myopia, Bardet-Biedl syndrome or retinitis pigmentosa genes. There was a novel heterozygous variant identified in exon 36 of the SLIT2 gene of the proband, c.4220A $>$ G, p.D1407G. The 


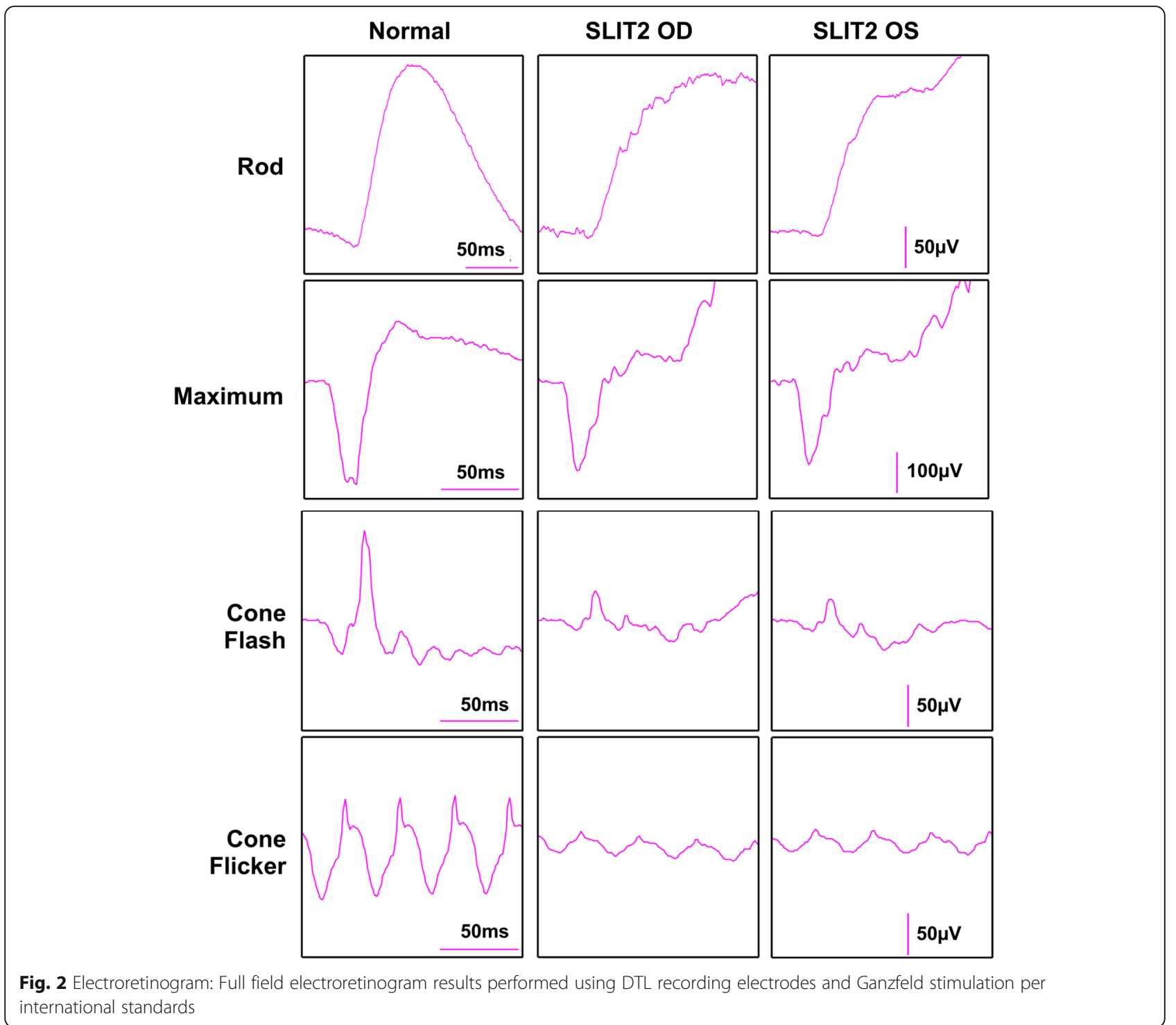

unaffected mother, father, brother and maternal aunt did not carry this mutation, indicating a likely de novo occurrence in the patient (Additional file 1: Tables S2-S5). A primary sequence analysis in SIFT [32] and PolyPhen-2 [33] predicted the mutation to be tolerated, while PROVEAN [34] predicted deleterious effects on SLIT2 function (Additional file 1: Tables S6-S8).

We performed computer-based structural modeling to gain insight into the pathogenicity of our patient's SLIT2 mutation [35-37]. SLIT2 gene encodes a 1529 amino acid extracellular protein which contains no transmembrane sequence $[6,7]$. All SLIT proteins share a common structure which includes an N-terminal signal peptide (SS), four tandem leucine-rich repeats (LRR), a sequence of EGF repeats, a conserved ALPS spacer (laminin G) followed by a C-terminal cysteine knot (CTCK), which serves as a dimerization motif (Fig. 4a) [6, 7]. Structures of several human SLIT2 domains have been solved by $\mathrm{x}$-ray crystallography, but the full-length structure remains to be determined $[9,21,38]$. We therefore generated a three-dimensional model of the full-length SLIT2 structure using a domain assembly approach [39] (Fig. 4b; Additional file 1). Our structural model placed the p.D1407G mutation on the SLIT2-C fragment in the 8th EGF-like repeat domain. Previously-identified CAKUT mutations (A98T, S566 N, and K904 N) were all located on the LRR domains of the SLIT-N fragment [19]. The D1407 amino acid was shown to be highly conserved throughout vertebrates, consistent with the evolutionary conservation of exon 36 measured in PhyloP [40] (Additional file 1: Table S9). This finding suggested that mutation of this amino acid from aspartate to a different amino acid would not be well tolerated and likely lead to negative effects, such as those observed in the patient (Fig. 4c). Further analysis showed 


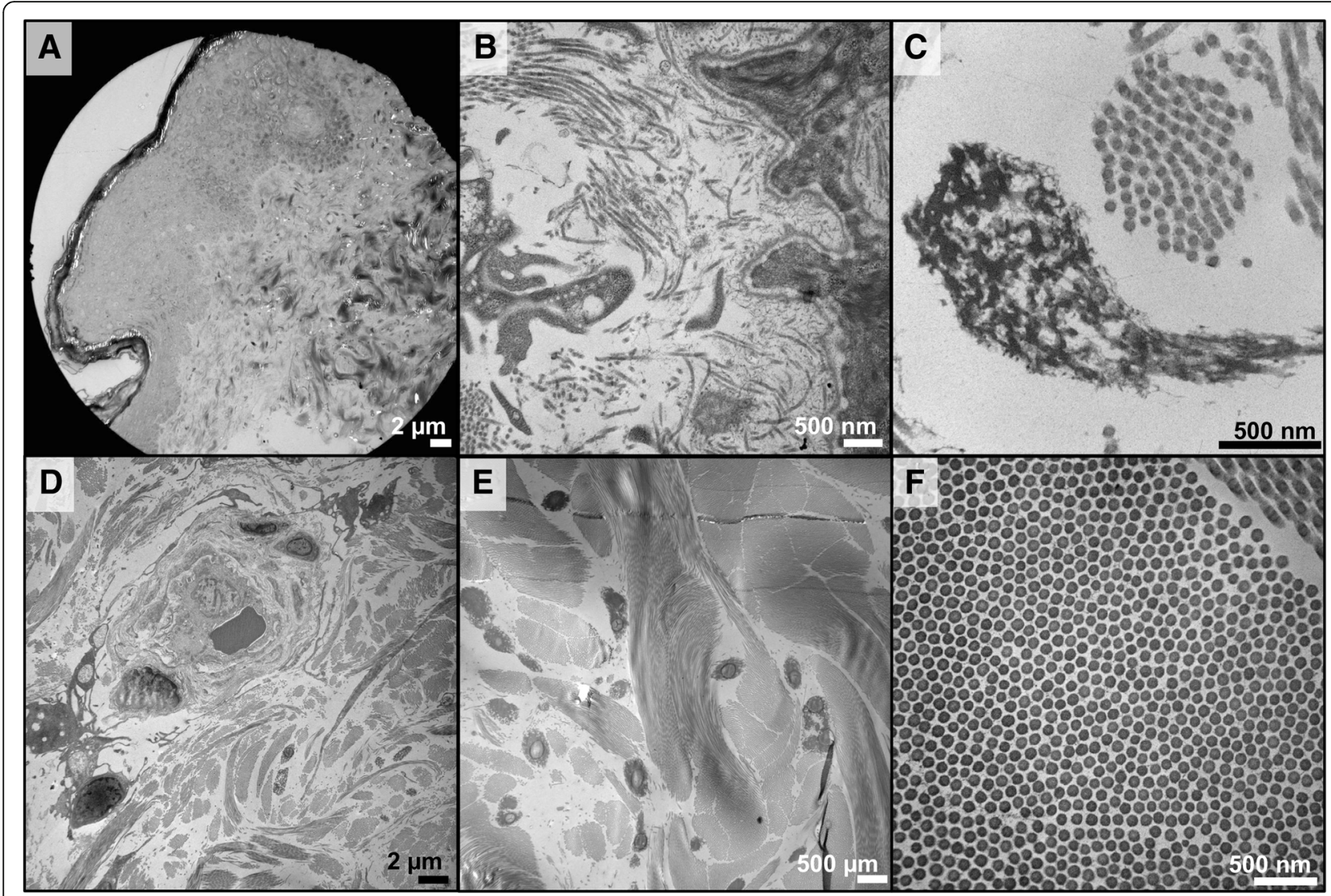

Fig. 3 Histological analysis reveals connective tissue abnormalities: a Skin biopsy showing considerably thickened epithelium, particularly near the hair follicles. Image taken at 220x magnification; scale bars $=10 \mu \mathrm{m}$. b Skin biopsy showing high density of collagen in the papillary dermis. Image taken at 19000 $\times$ magnification; scale bars $=500 \mathrm{~nm}$. c Skin biopsy showing elastin in the shallow and deep papillary dermis that is moth eaten and lacks associated micro-fibrils. Image taken at 50000x magnification; scale bars $=500 \mathrm{~nm}$. $\mathbf{d}$ Skin biopsy showing macrophages adjacent to the capillaries. Image taken at 3500x magnification; scale bars $=2 \mu \mathrm{m}$. e Skin biopsy showing dimples at the cores of the elastin fibrils that seem to indicate a higher than normal density of elastin fibrils in the reticular dermis. Image taken at 3500× magnification; scale bars $=2 \mu \mathrm{m}$. $\mathbf{f}$ Skin biopsy showing collagen fibrils in the reticular dermis are abnormally small and uniform in diameter. Image taken at 29000x magnification; scale bars = 500 nm

that the D1407 residue is restrained by an adjacent cysteine-disulfide bridge, one of three highly-conserved disulfide linkages in this domain (Fig. 4d). The p.D1407G mutation is predicted to cause a decrease in stability $(\Delta \Delta \mathrm{G}$ of $-0.35 \mathrm{kcal} / \mathrm{mol}$ ), likely due to the increased conformational flexibility of the substituted glycine (Fig. 4d) [28]. Additionally, this substitution leads to a loss of negative charge (Fig. 4e). Since EGF-like domains are known to be involved in mediating protein-protein interactions, this loss of charge may affect interactions to SLIT2 binding partners that are critical to its molecular function $[41,42]$.

\section{Discussion}

In this case we present a 15-year old boy with a tetrad of congenital myopia, anisometropia, obesity, and connective tissue abnormalities. The patient's skin biopsy indicated an absence in the coordination of elastic fiber formation and the integration of elastin fibers with collagen fibers, suggesting an underlying connective tissue disorder. Whole exome sequencing revealed a novel heterozygous variant in exon 36 of the SLIT2 gene of the proband, c.4220A > G, p.D1407G. The heterozygous nature of the variant associated with the patient's phenotype suggests, most likely, a potential gain of function in the expressed protein, although paternity was not tested in the pedigree. Based on data from the NHLBI Exome Sequencing Project (ESP), the c.2240A > G alteration in SLIT2 was not observed among 6503 individuals tested (0.0\%) (assessed December, 2017). Furthermore, the D1407 amino acid was shown to be highly conserved throughout vertebrates, meaning that evolution of this amino acid from aspartate to a different amino acid is likely not well tolerated and leads to negative effects.

It is now known that the SLIT2/ROBO4 paired signaling impedes the pathologic formation of blood vessels and reduces vascular leakage in mouse models [43]. These pathological processes are hallmarks of age-related macular degeneration, premature retinopathy, and diabetic 


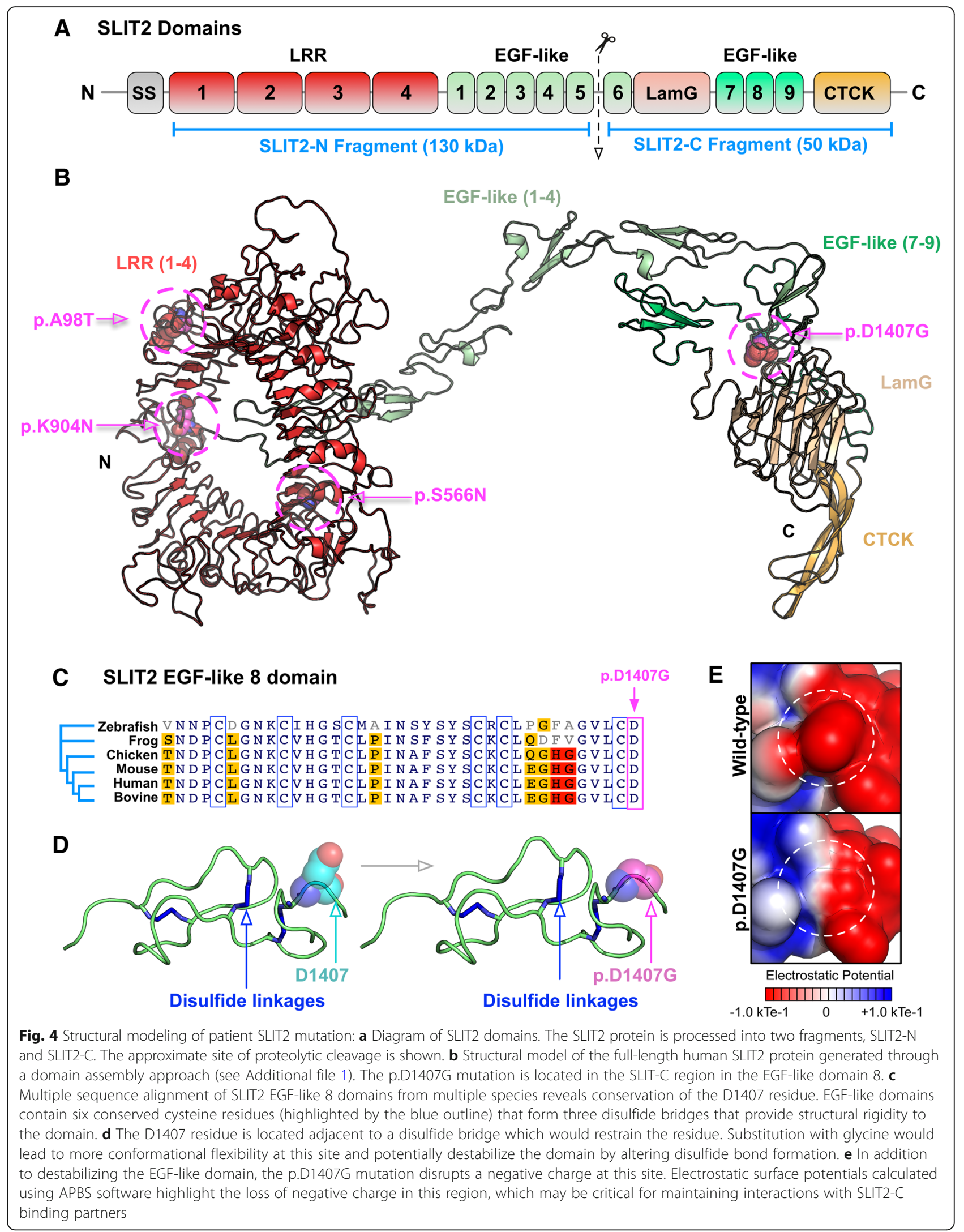


retinopathy. The SLIT2/ROBO receptor signaling also helps to guide retinal ganglion cell axons to extend into the optic fiber layer in the dorsal periphery of the retina and project toward the optic disc [44]. Furthermore, it has been shown that Slit binds to type IV Collagen, and that this interaction stabilizes the Slit molecule in the basement membrane at the surface of the tectum, contributing to the retinotectal architecture. Collagen IV appears to organize the cellular scaffold at the surface of the tectum, which consists of radial glial end feet and secreted factors such as Slit, which together, serve as laminar positional cues to ingrowing retinal axons [45]. It is well established that myopia can be caused by increased axial length of the eye and pathologic changes in the sclera, including scleral thinning, particularly in the posterior pole of the eye. The sclera is a dense connective tissue that maintains the eye shape and is comprised mainly of extracellular matrix which is primarily made up of collagen. In the development of myopia, there is a significant loss of scleral tissue weight that is associated with a narrowing and disconnection of collagen fiber bundles and a reduction in the number of them, especially at the posterior pole. As myopia continues to develop, the thinning of existing collagen fiber bundles is accompanied by a shift in collagen fiber diameter distribution such that the sclera contains more small collagen fibers, which accounts for the lower tensile strength of the tissue [46]. These pathologic findings related to collagen in myopia development, along with the findings in this case of the SLIT2 mutation and abnormal collagen in the patient's skin biopsy, suggest a potential role of the SLIT2 mutation in defective connective tissue formation, indicating a more systemic genetic syndrome that encompasses the patient's congenital myopia.

The long-term systemic consequences of SLIT2 c.4220A > G, p.D1407G in connective tissue, the heart, brain, eye, vasculature, and the kidney are unknown. SLIT2 is found in the extracellular matrix of these organs. A single mutation in another extracellular matrix protein, fibrillin, initially causes myopia in children and then predisposes systemic complications later in life [1]. Structural modeling of this mutation has provided some initial insight into its pathogenicity. Our analysis suggests that this mutation destabilizes SLIT2 interactions with its binding partners by disrupting a highly conserved residue in the EGF-like domain 8. This mutation is distinct from previously-published CAKUT mutations (which are located in the LRR domains) and offer a potential explanation for the tissue specificity of their related phenotypes [19].

\section{Conclusions}

This case provides compelling evidence of the SLIT2 point mutation as a novel gene associated with the identified ocular findings and connective tissue abnormalities.
These conclusions are limited, as they are derived from a singular case thus far, and there exists the possibility that there are other unidentified variants contributing to aspects of the patient's phenotype, such as obesity, that may be unrelated to the SLIT2 mutation [47]. This further underscores the importance of future studies to shed light on the role of SLIT2 in connective tissue pathophysiology, obesity, and ocular disease.

\section{Additional file}

Additional file 1: Table S1. BMI observations for proband and brother. Table S2. SLIT2 candidate gene. Table S3. SLIT2 mutation whole exome sequencing results. Table S4. Familial genetic co-segregation analysis by whole exome sequencing. Table S5. Variant filtering based on bioinformatics and interpretation. Table S6. Prediction of effects of SLIT2 mutations using the SIFT server. Table S7. Prediction of effects of SLIT2 mutations using the PolyPhen-2 server. Table S8. Prediction of effects of SLIT2 mutations using the PROVEAN server. Table S9. PhyloP conservation scores for SLIT2. (DOCX $35 \mathrm{~kb}$ )

\section{Abbreviations}

AF: Autofluorescence; CAKUT: Congenital abnormalities of the kidney and urinary tract; COL2A1: Collagen 2 alpha 1 gene; CTCK: C-terminal cysteine knot; ESP: Exome sequencing project; ffERG: Full-field electroretinogram; ROBO: Roundabout receptor; SD-OCT: Spectral domain optical coherence tomography; UMODL1: Uromodulin-like 1 gene

\author{
Acknowledgements \\ We wish to thank Irene H. Maumenee and Lynn Sakai for technical \\ assistance.
}

\section{Funding}

Supported, in part, by grants from National Eye Institute, NIH [P30EY019007, R01EY018213, R01EY024698, R01EY026682, R21AG050437, R24EY019861], National Cancer Institute Core [5P30CA013696], the Research to Prevent Blindness (RPB) Physician-Scientist Award, unrestricted funds from RPB, New York, NY, USA. J.D.S is supported by the RPB Medical Student Eye Research Fellowship. S.H.T. is a member of the RD-CURE Consortium and is supported by the Tistou and Charlotte Kerstan Foundation and the Schneeweiss Stem Cell Fund, New York State [C029572]. VBM and AGB are supported by NIH grants [R01EY026682, R01EY024665, R01EY025225, R01EY024698 and

R21AG050437], The Doris Duke Charitable Foundation Grant \#2013103, and Research to Prevent Blindness (RPB), New York, NY. GV is supported by NIH grants [F30EYE027986 and T32GM007337].

\section{Availability of data and materials}

The data generated during and/or analyzed during the current study are available in the supplemental online content and from the corresponding author on reasonable request.

\section{Authors' contributions}

Study concept and design: SHT. Acquisition of data: KYL, JDS, GV, and RJ. Analysis and interpretation of data: KYL, JDS, GV, RJ, AGB, VBM, and SHT. Drafting of the manuscript: KYL, JDS, GV, RJ, AGB, VBM, and SHT. Critical revision of the manuscript for important intellectual content: $A G B, V B M$, and SHT. Bioinformatic analysis: GV. Obtained funding: SHT. Administrative, technical, and material support: SHT. Study supervision: SHT. All authors read and approved the final manuscript.

Ethics approval and consent to participate

This retrospective case study was approved by the Columbia University Medical Center Internal Review Board, protocol AAAB6560, and adhered to the tenets of the Declaration of Helsinki. 


\section{Consent for publication}

Written and verbal informed consent was obtained from participants. The Data presented in this study, including images and genetic testing results, are not identifiable to individual patients.

\section{Competing interests}

The authors declare that they have no competing interests.

\section{Publisher's Note}

Springer Nature remains neutral with regard to jurisdictional claims in published maps and institutional affiliations.

\begin{abstract}
Author details
${ }^{1}$ Stony Brook University School of Medicine, Stony Brook, NY, USA. ${ }^{2}$ Jonas Children's Vision Care, and Bernard and Shirlee Brown Glaucoma Laboratory, New York, USA. ${ }^{3}$ Department of Ophthalmology, Columbia University, New York, NY, USA. ${ }^{4}$ Department of Medicine, Reading Hospital, West Reading, PA, USA. ${ }^{5}$ Omics Laboratory, Stanford University, Palo Alto, CA, USA. ${ }^{6}$ Department of Ophthalmology, Byers Eye Institute, Stanford University, Palo Alto, CA, USA ${ }^{7}$ Medical Scientist Training Program, University of lowa, lowa City, IA, USA. ${ }^{8}$ Weill Cornell Medical College, New York, NY, USA. ${ }^{9}$ Departments of Molecular and Medical Genetics and Biochemistry and Molecular Biology, Oregon Health and Science University and Shriners Hospital for Children, Portland, USA. ${ }^{10}$ Department of Pediatrics, University of lowa, lowa City, IA, USA. ${ }^{11}$ Palo Alto Veterans Administration, Palo Alto, CA, USA. ${ }^{12}$ Department of Pathology and Cell Biology, Stem Cell Initiative (CSCI), Institute of Human Nutrition, College of Physicians and Surgeons, Columbia University, New York, NY, USA. ${ }^{13}$ Harkness Eye Institute, Columbia University Medical Center, 635 West 165th Street, Box 212, New York, NY 10032, USA.
\end{abstract}

\section{Received: 3 October 2017 Accepted: 31 July 2018}

Published online: 15 August 2018

\section{References}

1. Guggenheim JA, Kirov G, Hodson SA. The heritability of high myopia: a reanalysis of Goldschmidt's data. J Med Genet. 2000;37(3):227-31.

2. Young TL. Dissecting the genetics of human high myopia: a molecular biologic approach. Trans Am Ophthalmol Soc. 2004;102:423-45.

3. Li YJ, Guggenheim JA, Bulusu A, Metlapally R, Abbott D, Malecaze F, Calvas P, Rosenberg T, Paget S, Creer RC, et al. An international collaborative family-based whole-genome linkage scan for high-grade myopia. Invest Ophthalmol Vis Sci. 2009;50(7):3116-27.

4. Hornbeak DM, Young TL. Myopia genetics: a review of current research and emerging trends. Curr Opin Ophthalmol. 2009;20(5):356-62.

5. Mordechai S, Gradstein L, Pasanen A, Ofir R, El Amour K, Levy J, Belfair N, Lifshitz T, Joshua S, Narkis G, et al. High myopia caused by a mutation in LEPREL1, encoding prolyl 3-hydroxylase 2. Am J Hum Genet. 2011;89(3):438-45.

6. Brose K, Bland KS, Wang KH, Arnott D, Henzel W, Goodman CS, TessierLavigne M, Kidd T. Slit proteins bind Robo receptors and have an evolutionarily conserved role in repulsive axon quidance. Cell. 1999;96(6): 795-806.

7. Li HS, Chen JH, Wu W, Fagaly T, Zhou L, Yuan W, Dupuis S, Jiang ZH, Nash W, Gick $C$, et al. Vertebrate slit, a secreted ligand for the transmembrane protein roundabout, is a repellent for olfactory bulb axons. Cell. 1999;96(6): 807-18

8. Marillat V, Cases O, Nguyen-Ba-Charvet KT, Tessier-Lavigne M, Sotelo C, Chedotal A. Spatiotemporal expression patterns of slit and robo genes in the rat brain. J Comp Neurol. 2002;442(2):130-55.

9. Morlot C, Thielens NM, Ravelli RB, Hemrika W, Romijn RA, Gros P, Cusack S, McCarthy AA. Structural insights into the slit-Robo complex. Proc Natl Acad Sci U S A. 2007;104(38):14923-8.

10. Wang KH, Brose K, Arnott D, Kidd T, Goodman CS, Henzel W, TessierLavigne M. Biochemical purification of a mammalian slit protein as a positive regulator of sensory axon elongation and branching. Cell. 1999; 96(6):771-84.

11. Fish JE, Wythe JD, Xiao T, Bruneau BG, Stainier DY, Srivastava D, Woo S. A slit/ miR-218/Robo regulatory loop is required during heart tube formation in zebrafish. Development. 2011:138(7):1409-19.

12. Grieshammer U, Le M, Plump AS, Wang F, Tessier-Lavigne M, Martin GR. SLIT2-mediated $\mathrm{ROBO} 2$ signaling restricts kidney induction to a single site. Dev Cell. 2004;6(5):709-17.
13. Kramer SG, Kidd T, Simpson JH, Goodman CS. Switching repulsion to attraction: changing responses to slit during transition in mesoderm migration. Science. 2001;292(5517):737-40.

14. London NR, Li DY. Robo4-dependent slit signaling stabilizes the vasculature during pathologic angiogenesis and cytokine storm. Curr Opin Hematol. 2011:18(3):186-90.

15. Ypsilanti AR, Zagar Y, Chedotal A. Moving away from the midline: new developments for slit and Robo. Development. 2010;137(12):1939-52.

16. Thompson H, Camand O, Barker D, Erskine L. Slit proteins regulate distinct aspects of retinal ganglion cell axon guidance within dorsal and ventral retina. J Neurosci. 2006;26(31):8082-91.

17. Svensson KJ, Long JZ, Jedrychowski MP, Cohen P, Lo JC, Serag S, Kir S, Shinoda K, Tartaglia JA, Rao RR, et al. A secreted Slit2 fragment regulates adipose tissue thermogenesis and metabolic function. Cell Metab. 2016; 23(3):454-66.

18. Peifer M, Fernandez-Cuesta L, Sos ML, George J, Seidel D, Kasper LH, Plenker $D$, Leenders F, Sun R, Zander T, et al. Integrative genome analyses identify key somatic driver mutations of small-cell lung cancer. Nat Genet. 2012; 44(10):1104-10.

19. Hwang DY, Kohl S, Fan X, Vivante A, Chan S, Dworschak GC, Schulz J, van Eerde AM, Hilger AC, Gee HY, et al. Mutations of the SLIT2-ROBO2 pathway genes SLIT2 and SRGAP1 confer risk for congenital anomalies of the kidney and urinary tract. Hum Genet. 2015;134(8):905-16.

20. Ohto U, Shibata T, Tanji H, Ishida H, Krayukhina E, Uchiyama S, Miyake K, Shimizu T. Structural basis of CpG and inhibitory DNA recognition by tolllike receptor 9. Nature. 2015;520(7549):702-5.

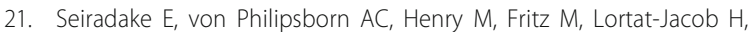
Jamin M, Hemrika W, Bastmeyer M, Cusack S, McCarthy AA. Structure and functional relevance of the Slit2 homodimerization domain. EMBO Rep. 2009;10(7):736-41.

22. Webb B, Sali A. Comparative Protein Structure Modeling Using MODELLER. Curr Protoc Protein Sci. 2016:86:2 9 1-2 937.

23. Luca VC, Kim BC, Ge C, Kakuda S, Wu D, Roein-Peikar M, Haltiwanger RS, Zhu C, Ha T, Garcia KC. Notch-jagged complex structure implicates a catch bond in tuning ligand sensitivity. Science. 2017;355(6331):1320-4.

24. Wizemann H, Garbe JH, Friedrich MV, Timpl R, Sasaki T, Hohenester E. Distinct requirements for heparin and alpha-dystroglycan binding revealed by structure-based mutagenesis of the laminin alpha2 LG4-LG5 domain pair. J Mol Biol. 2003;332(3):635-42.

25. Kershaw NJ, Church NL, Griffin MD, Luo CS, Adams TE, Burgess AW. Notch ligand delta-like1: X-ray crystal structure and binding affinity. Biochem J. 2015;468(1):159-66.

26. Kelley LA, Mezulis S, Yates CM, Wass MN, Sternberg MJ. The Phyre2 web portal for protein modeling, prediction and analysis. Nat Protoc. 2015;10(6): 845-58.

27. Xu D, Jaroszewski L, Li Z, Godzik A. AIDA: ab initio domain assembly for automated multi-domain protein structure prediction and domain-domain interaction prediction. Bioinformatics. 2015;31(13):2098-105.

28. Schymkowitz J, Borg J, Stricher F, Nys R, Rousseau F, Serrano L. The FoldX web server: an online force field. Nucleic Acids Res. 2005;33(Web Server issue):W382-8.

29. Konecny R, Baker NA, McCammon JA. iAPBS: a programming interface to Adaptive Poisson-Boltzmann Solver (APBS). Comput Sci Discov. 2012; 5(1).

30. PyMOL, New York. http://www.pymol.org/.

31. Kuczmarski RJ, Ogden CL, Guo SS, Grummer-Strawn LM, Flegal KM, Mei $Z$, Wei $R$, Curtin LR, Roche AF, Johnson CL. CDC growth charts for the United States: methods and development. Vital Health Stat 11. 2000; 2002(246):1-190.

32. Sim NL, Kumar P, Hu J, Henikoff S, Schneider G, Ng PC. SIFT web server: predicting effects of amino acid substitutions on proteins. Nucleic Acids Res. 2012:40(Web Server issue):W452-7.

33. Adzhubei I, Jordan DM, Sunyaev SR. Predicting functional effect of human missense mutations using PolyPhen-2. Curr Protoc Hum Genet. 2013; Chapter 7:Unit7 20.

34. Choi $Y$, Chan AP. PROVEAN web server: a tool to predict the functional effect of amino acid substitutions and indels. Bioinformatics. 2015;31(16): 2745-7.

35. Moshfegh Y, Velez G, Li Y, Bassuk AG, Mahajan VB, Tsang SH. BESTROPHIN1 mutations cause defective chloride conductance in patient stem cellderived RPE. Hum Mol Genet. 2016;25(13):2672-80. 
36. Cox AJ, Darbro BW, Laxer RM, Velez G, Bing X, Finer AL, Erives A, Mahajan VB, Bassuk AG, Ferguson PJ. Recessive coding and regulatory mutations in FBLIM1 underlie the pathogenesis of chronic recurrent multifocal osteomyelitis (CRMO). PLoS One. 2017;12(3):e0169687.

37. Toral MA, Velez G, Boudreault K, Schaefer KA, Xu Y, Saffra N, Bassuk AG, Tsang SH, Mahajan VB. Structural modeling of a novel SLC38A8 mutation that causes foveal hypoplasia. Mol Genet Genomic Med. 2017;5(3):202-9.

38. Morlot C, Hemrika W, Romijn RA, Gros P, Cusack S, McCarthy AA. Production of Slit2 LRR domains in mammalian cells for structural studies and the structure of human Slit2 domain 3. Acta Crystallogr D Biol Crystallogr. 2007; 63(Pt 9):961-8.

39. Velez G, Tsang SH, Tsai YT, Hsu CW, Gore A, Abdelhakim AH, Mahajan M, Silverman RH, Sparrow JR, Bassuk AG, et al. Gene therapy restores Mfrp and corrects axial eye length. Sci Rep. 2017;7(1):16151.

40. Pollard KS, Hubisz MJ, Rosenbloom KR, Siepel A. Detection of nonneutral substitution rates on mammalian phylogenies. Genome Res. 2010;20(1):110-21.

41. Stenflo J, Stenberg Y, Muranyi A. Calcium-binding EGF-like modules in coagulation proteinases: function of the calcium ion in module interactions. Biochim Biophys Acta. 2000;1477(1-2):51-63.

42. Darbro BW, Mahajan VB, Gakhar L, Skeie JM, Campbell E, Wu S, Bing X, Millen KJ, Dobyns WB, Kessler JA, et al. Mutations in extracellular matrix genes NID1 and LAMC1 cause autosomal dominant Dandy-Walker malformation and occipital cephaloceles. Hum Mutat. 2013:34(8):1075-9.

43. Jones CA, London NR, Chen H, Park KW, Sauvaget D, Stockton RA, Wythe JD, Suh W, Larrieu-Lahargue F, Mukouyama YS, et al. Robo4 stabilizes the vascular network by inhibiting pathologic angiogenesis and endothelial hyperpermeability. Nat Med. 2008;14(4):448-53.

44. Down M, Willshaw DA, Pratt T, Price DJ. Steerable-filter based quantification of axonal populations at the developing optic chiasm reveal significant defects in Slit2(-/-) as well as Slit1(-/-)Slit2(-/-) embryos. BMC Neurosci. 2013;14:9.

45. Xiao T, Staub W, Robles E, Gosse NJ, Cole GJ, Baier H. Assembly of laminaspecific neuronal connections by slit bound to type IV collagen. Cell. 2011; 146(1):164-76

46. Yang Y, Li X, Yan N, Cai S, Liu X. Myopia: a collagen disease? Med Hypotheses. 2009;73(4):485-7.

47. Posey JE, Harel T, Liu P, Rosenfeld JA, James RA, Coban Akdemir ZH, Walkiewicz M, Bi W, Xiao R, Ding Y, et al. Resolution of disease phenotypes resulting from multilocus genomic variation. N Engl J Med. 2017:376(1):21-31

Ready to submit your research? Choose BMC and benefit from:

- fast, convenient online submission

- thorough peer review by experienced researchers in your field

- rapid publication on acceptance

- support for research data, including large and complex data types

- gold Open Access which fosters wider collaboration and increased citations

- maximum visibility for your research: over $100 \mathrm{M}$ website views per year

At $\mathrm{BMC}$, research is always in progress.

Learn more biomedcentral.com/submissions 